\title{
Accumulation of advanced glycation end (AGEs) products in intensive care patients: an observational, prospective study
}

\author{
Wendela L Greven*1,2, Jitty M Smit2, Johannes H Rommes and Peter E Spronk1,3,4
}

\begin{abstract}
Background: Oxidative stress plays an important role in the course and eventual outcome in a majority of patients admitted to the intensive care unit (ICU). Markers to estimate oxidative stress are not readily available in a clinical setting. AGEs accumulation has been merely described in chronic conditions, but can also occur acutely due to oxidative stress. Since AGEs have emerged to be stable end products, these can be a marker of oxidative stress. Skin autofluorescence (AF) is a validated marker of tissue content of AGEs. We hypothesized that AGEs accumulate acutely in ICU patients.

Methods: We performed an observational prospective study in a medical surgical ICU in a university affiliated teaching hospital. All consecutively admitted ICU patients in a 2 month period were included. Skin AF was measured using an AGE reader in 35 consecutive ICU patients $>18 \mathrm{yrs}$. As a comparison, historical data of a control group $(n=231)$ were used. These were also used to calculate age-adjusted AF-levels $\left(A F_{\text {adj }}\right.$ ). Values are expressed as median and interquartile range $\left[P_{25}-P_{75}\right.$. Differences between groups were tested by non parametric tests. $P<0.05$ was considered statistically significant.

Results: $\mathrm{AF}_{\text {adj }}$ values were higher in ICU patients $(0.33$ [0.00 - 0.68]) than in controls $(-0.07[-0.29-0.24] ; P<0.001)$. No differences in skin $A F_{\text {adj }}$ were observed between acute or planned admissions, or presence of sepsis, nor was skin $A F_{\text {adj }}$ related to severity of disease as estimated by APACHE-II score, length of ICU, hospital stay or mortality.

Conclusion: Acute AGE accumulation in ICU patients was shown in this study, although group size was small. This can possibly reflect oxidative stress in ICU patients. Further studies should reveal whether AGE-accumulation will be a useful parameter in ICU patients and whether skin AF has a predictive value for outcome, which was not shown in this small study.
\end{abstract}

\section{Background}

Patients admitted to the intensive care unit (ICU) may develop multiple organ dysfunction syndrome (MODS). The pathogenesis of this deterioration of organ function involves oxidative stress caused by reactive oxygen species (ROS) [1]. Indeed, the prognosis and outcome of patients admitted to the ICU is dependent on the degree of oxidative stress [2]. Oxidative stress is associated with most conditions requiring intensive care: but how could oxidative stress be measured? Interestingly, no common

* Correspondence: wendelagreven@hotmail.com

1 Department of Intensive Care Medicine, Gelre hospitals, location Lukas, Apeldoorn, the Netherlands

Full list of author information is available at the end of the article strategy exists about its measurement and many methods of estimating oxidative stress have proven unreliable [3]. Moreover most parameters need complicated blood sample measurements.

Advanced glycation endproducts (AGEs) accumulate with oxidative stress and can be very easily and quickly measured, non-invasively. AGEs comprise a diverse class of compounds that link to proteins and accumulate in long-lived tissues. Several AGEs encompass a characteristic autofluorescence pattern when illuminating skin [4]. Using this specific property; skin AGE accumulation can be assessed by the AGE reader, a non-invasive, quick method, that has been thoroughly validated with AGEs measured in skin biopsies [4]. AGEs can be formed by 
several pathways [5]. In addition to the classical pathway, known as the Maillard reaction, other pathways are important, such as formation by reactive carbonyl compounds, which may form rapidly under oxidative stress [6]. In contrast to most other markers of oxidative stress, AGEs, once formed are stable compounds. They accumulate with age and play an important role in the development of end organ damage in several conditions such as diabetes, atherosclerosis and renal failure [7-9]. Two mechanisms may play a role. First, AGE modification directly alters the function and structure of extracellular matrix proteins [10]. Second, AGEs modulate cellular functions through ligation of specific cell surface receptors, such as the receptor for AGEs (RAGE) [11].

AGE accumulation has been described merely in chronic diseases. But since oxidative stress also augments AGE formation, and oxidative stress occurs in patients in the ICU, we hypothesize an acute rise of AGE levels in patients admitted to the ICU.

\section{Methods \\ Design}

This observational study, without interference with usual care was carried out in a university affiliated teaching hospital with an ICU with a mixed medical-surgical closed-format setting with 10 beds. Due to the observational nature of the study without changes in therapy, the requirement for obtaining informed consent was waived by the institutional review board.

\section{AGE measurements}

AGE levels were measured with the AGE-reader, a noninvasive, portable device, which has been thoroughly validated with AGEs measured in skin biopsies [4], DiagnOptics BV, Groningen, the Netherlands. All measurements were performed within 24 hours after admission, consistently by the same observer (WLG). The AGE-reader illuminates a skin surface of $1 \mathrm{~cm}^{2}$, with an excitation light source between $300-420 \mathrm{~nm}$. Only light from the skin is measured with a spectrometer in the $300-600 \mathrm{~nm}$ range, using 200 um glass fiber. Autofluorescence (AF) will be calculated as follows: ratio between average light intensity, measured in the range $420-600 \mathrm{~nm}$ and the average light intensity in the range 300-420 nm (emission/excitation) and this ratio is expressed as arbitrary units. Three consecutive measurements, from each patient were taken of which the mean was calculated.

\section{Patients}

Patients were included if skin AF could be measured within $24 \mathrm{hrs}$ after admission. Patients with coloured skin were excluded, because the AGE reader had not yet been validated in patients with coloured skin. Patients with diabetes, liver cirrhosis or renal clearance below $35 \mathrm{ml} /$ min were also excluded, because these conditions are known to cause AGE accumulation.

\section{Controls}

A formerly studied group of healthy volunteers (231 individuals, seen in the outpatient clinic for preoperative evaluation without a history of diabetes, cardiovascular events or renal disease, and all within ASA Class I or II criteria) was used to verify normal AGE levels in healthy individuals (see reference [12] for details)[12]. AGE data were plotted against calendar age to yield a standard skin AF level for each age since AGEs accumulate with age (figure 1). Subsequently, the age-adjusted skin $\mathrm{AF}\left(\mathrm{AF}_{\text {adj }}\right)$ was calculated according the following formula: skin $\mathrm{AF}_{\text {adj }}$ level $=$ skin AF measured $-(0.9378+(0.0233 *$ age $))$ for both patients and controls. After the calculation the skin $\mathrm{AF}_{\text {adj }}$ level for controls approaches zero.

\section{Statistics}

Statistical analyses were performed using SPSS 9.5 for WINDOWS. Non parametric tests were applied. All values are expressed as (median [interquartile range; $\mathrm{P}_{25}$ $\left.\mathrm{P}_{75}\right]$ ). A P-value $<0.05$ was defined to indicate statistical significance.

\section{Results}

\section{Patients}

Thirty-five consecutive ICU patients, 21 male, 14 female were included. The median age in patients was 74 years [57 - 80]. Patient characteristics are shown in table 1. APACHE-II scores as well as length of stay in the ICU were comparable to a one year period preceding this study (data not shown).

\section{Skin autofluorescence measurements}

Absolute skin AF levels were higher in ICU patients (2.81 [2.28-3.34]) as compared to controls (2.07 [1.74-2.47]; $\mathrm{P}<$ 0.001). However, ICU patients were older (74 [57-80 years]) than control subjects (51 [39-67 years]; $\mathrm{P}<0.001$ ). In view of the established relation between AGE-levels and calendar age, all further analyses were based on skin $\mathrm{AF}_{\text {adj }}$ (adjusted for age). After the correction for age, skin $\mathrm{AF}_{\text {adj }}$ was still higher in patients admitted to the ICU $(0.33$ [0.00 - 0.68]) than in controls $(-0.07$ [-0.29 - 0.24]; P $<0.001$ ) (figure 2).

\section{Associations with other parameters}

No associations were found between skin AF-adj and disease severity as estimated by APACHE-II scores $(\mathrm{R}=$ $0.068)$, ICU length of stay $(R=0.004 \mid)$, mortality $(p=$ $0.905)$, nor with sepsis during ICU stay ( $\mathrm{p}=0.18)$, the reason for ICU admission ( $\mathrm{p}=0.544)$ or the urgency of admission ( $p=0.292$ ). In addition, no associations could be found between skin AF-adj and levels of albumin $(\mathrm{R}=$ 


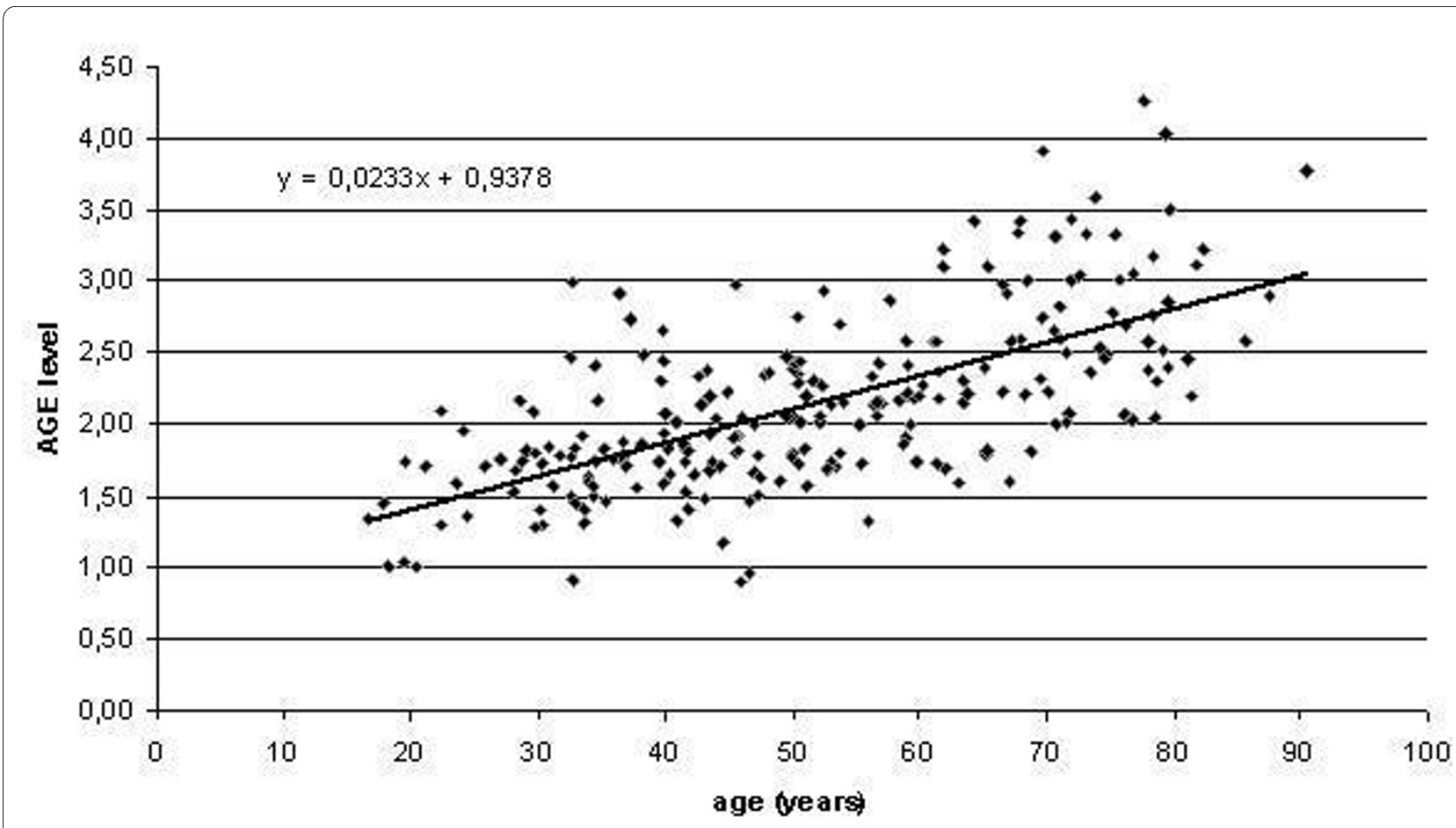

Figure 1 Skin AF levels in control subject show a linear correlation with age, according to an equation: skin AF level $=0.9378+(0.0233 *$ age) $\left(R^{2}=0.43\right)$.

$0.036)$, highest glucose level $(\mathrm{R}=0.016)$ or the lowest $\mathrm{pH}$ $(R=0.00)$ in the first 24 hours of ICU stay.

\section{Discussion}

This study shows acute AGE accumulation in ICU patients in a direct way by skin auto fluorescence. In this study the accumulation was not associated with disease severity, ICU length of stay or mortality.

Acute AGE accumulation is most likely mediated by oxidative stress, as the classical Maillard reaction is a slow non-enzymatic reaction. Oxidative stress causes formation of reactive carbonyl compounds, which react with protein to form AGEs [6]. Also blocking nitric oxide activity causes the production of reactive oxygen species [13]. Moreover binding of AGEs to RAGE generates intracellular reactive oxygen species $[14,15]$. This results in diminished reduced glutathione, and ascorbic acid. Depletion of glutathione leads to reduced glyoxalase-1 recycling and decreased in situ activity. Glyoxalase-1, however, has an important role in reducing the cellular AGE load [16,17]. Hence, an acute event could result in acute oxidative stress in the ICU patient, concomitant AGE accumulation, which itself could cause more oxidative stress, thus potentially causing a vicious cycle with progressive multiple organ failure.

The question is whether AGE accumulation is harmful? At least when evaluating chronic accumulation, AGE lev- els predict future microvascular and cardiovascular events in diabetic patients better than HbA1c $[8,9,18]$. Moreover skin AGE accumulation predicts (cardiovascular) mortality in hemodialysis patients and in patients with type 2 diabetes $[7,19]$. In addition, interventions aiming to modulate AGE accumulation have proved to alleviate end-organ damage in animal models [20]. This may support the idea about AGEs playing a causal and potentially predictive role in end organ damage. In contrast to these chronic accumulation of AGEs, recent research is focussed on the less known acute AGE accumulation. One may hypothesize that this acute AGE accumulation, as seen in our study, may be harmful because of intracellular ROS formation as well as depletion of antioxidant mechanisms $[15,16]$. In ICU patients, one study showed elevated levels of soluble AGE receptors (sRAGE) at admission in septic patients [21]. Furthermore, application of an extracellular decoy for RAGE ligands, improves survival in mice after induction of sepsis, suggesting that RAGE is a central player in perpetuating the innate immune response [22]. Also, AGEs content measured in pericardial fluids seemed to have a prognostic factor after cardiac surgery [23] and plasma levels of sRAGE was associated with increased severity of lung injury and increased mortality in patients with acute lung injury [24]. In addition, plasma sRAGE levels predicted length of stay in ICU in patients after lung transplanta- 
Table 1: Patient characteristics

\begin{tabular}{lc}
\hline & ICU patients \\
\hline $\mathrm{N}$ & 35 \\
Age (years) & $74[57-80]$ \\
Skin AF level & $2.81[2.28-3.34]$ \\
Skin AF-adj & $0.33[0.00-0.68]$ \\
ICU LOS (days) & $3.00[2.00-6.25]$ \\
hospital LOS (days) & $13.50[8.50-24.25]$ \\
APACHE II & $13.0[10.0-16.0]$ \\
$\%$ died, during ICU-stay & $14.3 \%$ \\
$\%$ ventilated & $94.3 \%$ \\
Admission type & \\
$\%$ acute medical & $17.1 \%$ \\
$\%$ acute surgical & $40.0 \%$ \\
$\%$ planned & $42.9 \%$ \\
First 24 hrs of ICU stay & \\
highest glucose level (mmol/I) & $8.5[6.5-11.9]$ \\
lowest pH & $7.41[7.36-7.44]$ \\
lowest albumin (g/l) & $22[15-24]$ \\
\hline LOS = length of stay (days) & \\
Values are expressed as median and IQR $\left[\mathrm{P}_{25}-\mathrm{P}_{75}\right]$ & or percentages \\
\end{tabular}

tion [25]. This is in concordance with our data finding elevated AGE levels already at admission in comparison to control subjects. However, we were not able to find an association with disease severity, ICU length of stay, nor with mortality. Besides differences in case mix and mortality rate, this difference might be explained by the fact that plasma sRAGE levels are not reflecting actual AGE

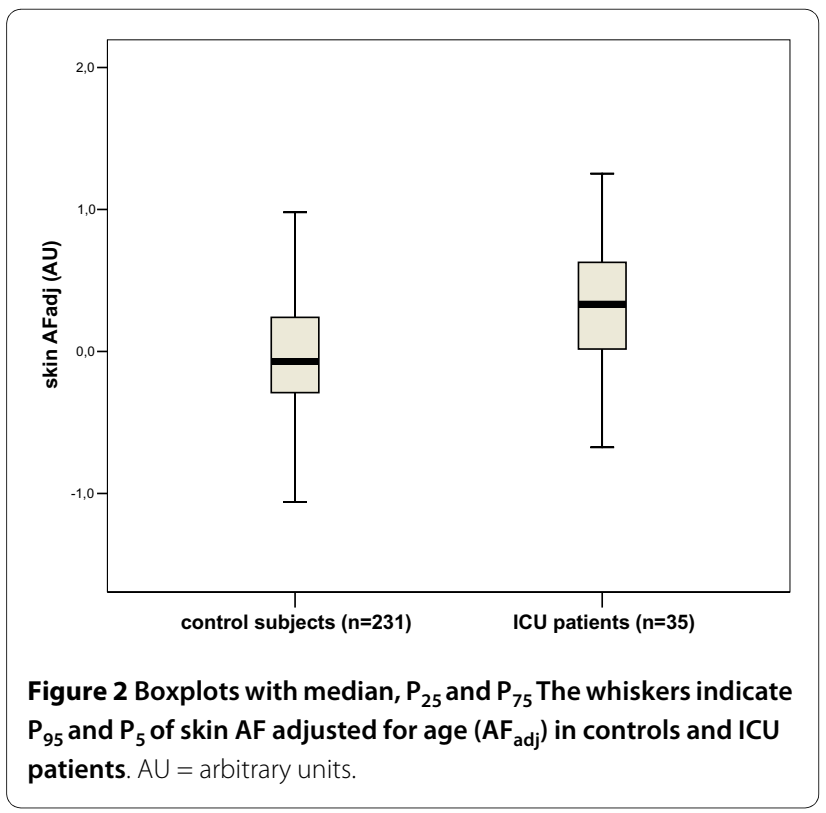

accumulation, thus yielding different results. We did not measure plasma sRAGE in our patients. More research, with larger numbers of patients, and in defined subgroups, should be carried out to address these issues.

Several study limitations need to be addressed. First, this is a small, single center study. Hence, the results may be quite different in other case-mixes in other ICUs. Secondly, this is a small series of patients. Nevertheless, they are probably a reasonable reflection of admissions to our ICU, because the composition of the patient characteristics did not differ with those in a 1 year period preceding this study. Thirdly, the AGE reader itself has not been formally validated for use in an ICU setting since all previous studies have been done in outclinic patients. One might argue that factors like edema could have influenced the results. Indeed, because water is not autofluorescent, values could be mildly reduced in the presence of substantial edema in the arm that was measured. However, this should be structurally addressed in further studies. Fourth; patients with conditions, known to cause AGE accumulation were not included in this study. So AGE accumulation is therefore most likely caused by the ICU admission itself. But the design of this study was crosssectional, so skin AF values before ICU admission of these particular patients are unknown. Further studies, should maybe focus on longitudinal skin AF measurements to show acute accumulation with ICU admission in the same patient.

In conclusion, acute AGE accumulation occurs in ICU patients, which probably reflects oxidative stress. The group was too small to allow any conclusions on the possible predictive value of skin $\mathrm{AF}$ for prognosis for patients on the ICU. Further studies should reveal whether measurement of AGE-accumulation will be a useful parameter in ICU patients.

\section{Conclusion}

Acute AGE accumulation was shown in this small group of ICU patients, which probably reflects oxidative stress. The group was too small to allow any conclusions on the possible predictive value of skin $\mathrm{AF}_{\text {adj }}$ for outcome. Further studies should reveal whether AGE-accumulation will be a useful parameter in ICU patients.

\section{Abbreviations}

AGEs: advanced glycation end products; AF: autofluorescence; ICU: intensive care unit; RAGE: receptor for advanced glycation end products; LOS: length of stay; AU: arbitrary units; ROS: reactive oxygen species.

\section{Competing interests}

Dr J.M. Smit is one of the founders of DiagnOptics BV, the company that manufactures and markets the AGE reader

The other authors declare that they don't have any competing interests. This study was not funded. DiagnOptics BV kindly provided the AGE-reader for the measurements. 


\section{Authors' contributions}

WLG carried out the measurements, did the analysis and interpretation of the data, and wrote the manuscript

JMS has made substantial contribution to the design and revised the manuscript critically for important intellectual content

JHR has revised the manuscript critically for important intellectual content PES has made substantial contribution to the design, the analysis of the results and revised the manuscript critically for important intellectual content All authors read and approved the final manuscript.

\section{Acknowledgements}

none

\section{Author Details}

'Department of Intensive Care Medicine, Gelre hospitals, location Lukas, Apeldoorn, the Netherlands, ${ }^{2}$ Department of Internal Medicine, Gelre hospitals, location Lukas, Apeldoorn, the Netherlands, ${ }^{3}$ Department of Intensive Care Medicine, Academic Medical Center, Amsterdam, the Netherlands and ${ }^{4}$ HERMES critical care group, Academic Medical Center, Amsterdam, the Netherlands

Received: 18 June 2009 Accepted: 25 May 2010

Published: 25 May 2010

\section{References}

1. Abiles J, de la Cruz AP, Castano J, Rodriguez-Elvira M, Aguayo E, MorenoTorres $R$, et al:: Oxidative stress is increased in critically ill patients according to antioxidant vitamins intake, independent of severity: a cohort study. Crit Care 2006, 10:R146.

2. Motoyama T, Okamoto K, Kukita I, Hamaguchi M, Kinoshita Y, Ogawa H: Possible role of increased oxidant stress in multiple organ failure after systemic inflammatory response syndrome. Crit Care Med 2003, 31:1048-1052

3. Grune T, Berger MM: Markers of oxidative stress in ICU clinical settings: present and future. Curr Opin Clin Nutr Metab Care 2007, 10:712-717.

4. Meerwaldt R, Links T, Graaff R, Thorpe SR, Baynes JW, Hartog J, et al:: Simple noninvasive measurement of skin autofluorescence. Ann NY Acad Sci 2005, 1043:290-298.

5. Baynes JW, Thorpe SR: Glycoxidation and lipoxidation in atherogenesis. Free Radic Biol Med 2000, 28:1708-1716.

6. Miyata T, van Ypersele de SC, Kurokawa K, Baynes JW: Alterations in nonenzymatic biochemistry in uremia: origin and significance of "carbonyl stress" in long-term uremic complications. Kidney Int 1999, 55:389-399.

7. Meerwaldt R, Hartog JW, Graaff R, Huisman RJ, Links TP, den Hollander NC, et al:: Skin autofluorescence, a measure of cumulative metabolic stress and advanced glycation end products, predicts mortality in hemodialysis patients. J Am Soc Nephrol 2005, 16:3687-3693.

8. Meerwaldt R, Links TP, Graaff R, Hoogenberg K, Lefrandt JD, Baynes JW, et al:: Increased accumulation of skin advanced glycation end-products precedes and correlates with clinical manifestation of diabetic neuropathy. Diabetologia 2005, 48:1637-1644.

9. Meerwaldt R, Lutgers HL, Links TP, Graaff R, Baynes JW, Gans RO, et al: Skin autofluorescence is a strong predictor of cardiac mortality in diabetes. Diabetes Care 2007, 30:107-112.

10. Singh R, Barden A, Mori T, Beilin L: Advanced glycation end-products: a review. Diabetologia 2001, 44:129-146.

11. Schmidt AM, Hasu M, Popov D, Zhang JH, Chen J, Yan SD, et al:: Receptor for advanced glycation end products (AGEs) has a central role in vessel wall interactions and gene activation in response to circulating AGE proteins. Proc Natl Acad Sci USA 1994, 91:8807-8811.

12. Lutgers $H L$, Graaff R, Links TP, Ubink-Veltmaat LJ, Bilo HJ, Gans RO, et al: Skin autofluorescence as a noninvasive marker of vascular damage in patients with type 2 diabetes. Diabetes Care 2006, 29:2654-2659.

13. Goldin A, Beckman JA, Schmidt AM, Creager MA: Advanced glycation end products: sparking the development of diabetic vascular injury. Circulation 2006, 114:597-605.

14. Lander HM, Tauras JM, Ogiste JS, Hori O, Moss RA, Schmidt AM: Activation of the receptor for advanced glycation end products triggers a p21(ras)-dependent mitogen-activated protein kinase pathway regulated by oxidant stress. J Biol Chem 1997, 272:17810-17814.
15. Wautier MP, Chappey O, Corda S, Stern DM, Schmidt AM, Wautier JL: Activation of NADPH oxidase by AGE links oxidant stress to altered gene expression via RAGE. Am J Physiol Endocrinol Metab 2001, 280:E685-E694

16. Bierhaus A, Chevion S, Chevion M, Hofmann M, Quehenberger P, Illmer T, et al: Advanced glycation end product-induced activation of NFkappaB is suppressed by alpha-lipoic acid in cultured endothelial cells. Diabetes 1997, 46:1481-1490

17. Thornalley PJ: Cell activation by glycated proteins. AGE receptors, receptor recognition factors and functional classification of AGEs. Cell Mol Biol (Noisy-le-grand) 1998, 44:1013-1023.

18. Genuth S, Sun W, Cleary P, Sell DR, Dahms W, Malone J, et al:: Glycation and carboxymethyllysine levels in skin collagen predict the risk of future 10-year progression of diabetic retinopathy and nephropathy in the diabetes control and complications trial and epidemiology of diabetes interventions and complications participants with type 1 diabetes. Diabetes 2005, 54:3103-3111.

19. Lutgers HL, Gerrits EG, Graaff R, Links TP, Sluiter WJ, Gans RO, et al.: Skin autofluorescence provides additional information to the UK Prospective Diabetes Study (UKPDS) risk score for the estimation of cardiovascular prognosis in type 2 diabetes mellitus. Diabetologia 2009, 52:789-797.

20. Alderson NL, Chachich ME, Youssef NN, Beattie RJ, Nachtigal M, Thorpe SR, et al:: The AGE inhibitor pyridoxamine inhibits lipemia and development of renal and vascular disease in Zucker obese rats. Kidney Int 2003, 63:2123-2133.

21. Bopp C, Hofer S, Weitz J, Bierhaus A, Nawroth PP, Martin E, et al:: SRAGE is elevated in septic patients and associated with patients outcome. $J$ Surg Res 2008, 147:79-83.

22. Bopp C, Bierhaus A, Hofer S, Bouchon A, Nawroth PP, Martin E, et al: Bench-to-bedside review: The inflammation-perpetuating patternrecognition receptor RAGE as a therapeutic target in sepsis. Crit Care 2008, 12:201.

23. Simm A, Wagner J, Gursinsky T, Nass N, Friedrich I, Schinzel R, et al:: Advanced glycation endproducts: a biomarker for age as an outcome predictor after cardiac surgery? Exp Gerontol 2007, 42:668-675.

24. Calfee CS, Ware LB, Eisner MD, Parsons PE, Thompson BT, Wickersham N, et al: Plasma receptor for advanced glycation end products and clinical outcomes in acute lung injury. Thorax 2008, 63:1083-1089.

25. Calfee CS, Budev MM, Matthay MA, Church G, Brady S, Uchida T, et al.: Plasma receptor for advanced glycation end-products predicts duration of ICU stay and mechanical ventilation in patients after lung transplantation. J Heart Lung Transplant 2007, 26:675-680.

Pre-publication history

The pre-publication history for this paper can be accessed here: http://www.biomedcentral.com/1472-6890/10/4/prepub

doi: $10.1186 / 1472-6890-10-4$

Cite this article as: Greven et al., Accumulation of advanced glycation end (AGEs) products in intensive care patients: an observational, prospective study BMC Clinical Pathology 2010, 10:4

\section{Submit your next manuscript to BioMed Centra and take full advantage of:}

- Convenient online submission

- Thorough peer review

- No space constraints or color figure charges

- Immediate publication on acceptance

- Inclusion in PubMed, CAS, Scopus and Google Scholar

- Research which is freely available for redistribution 